\title{
Assessment of the Context for eHealth Development in the Philippines: A Work in Progress from 1997 to 2020
}

\author{
Jinky Leilanie Lu, $\mathrm{MOH}, \mathrm{PhD}^{1}$ and Portia Grace F. Marcelo, MD, $\mathrm{MPH}^{2}$ \\ ${ }^{1}$ National Institutes of Health, University of the Philippines Manila \\ ${ }^{2}$ Community Oriented Medical Education, College of Medicine, University of the Philippines Manila
}

\begin{abstract}
Introduction. eHealth is described by the World Health Organization (WHO) as the use of information and communication technologies (ICT) for health. The use of eHealth closes the gaps in terms of geographical barriers, time constraints, lack of healthcare professionals in healthcare and service delivery. This study is important as it provides the current landscape and status of eHealth in the Philippines. Hence, policymakers, program implementors as well as other stakeholders, including the public, will be able to know which eHealth and telemedicine services and products are available in various sectors of society, either private or government, what are the existing gaps in eHealth, and the trajectory in the future based on the guide of the World Health Organization - International Telecommunication Union (WHO-ITU).
\end{abstract}

Objectives. The objectives of the study are 1) to provide a landscape of eHealth in the Philippines since its start in the country; 2) to identify programs, services, and technology innovations implemented in the country on eHealth and telemedicine; and 3) to identify Philippine systems that correspond to the eHealth components laid out by WHO-ITU for a successful implementation of eHealth at a national level.

Methods. We conducted an extensive review of the literature and key informant interviews with eHealth experts in the Philippines. The literature review covered research and studies, gray literature, peer-reviewed journals, databases, and government statistics. The years covered in this study span a total of 24 years from 1997, which is the beginning of the information management system as an institutional approach in the country, to 2020. The assessment tool was based on the framework provided by the WHO-ITU on the context for eHealth development.

Results. The National Telehealth Center (NTHC) of the Philippines began with projects for 1) eLearning, 2) eMedicine, 3) eRecords, 4) eHealth Policy and Advocacy, and 5) eSurveillance. Telemedicine services are now being offered by hospitals in the country. This shows eHealth services, in general, and telemedicine are being utilized in not only targeting the poor, but also in giving faster, more efficient, and equally effective virtual health services to the general public, even the private-pay patients.

Conclusion. The sustainability of eHealth in the Philippines still depends on the national effort to institutionalize an eHealth structure and eHealth system where the various components are interrelated.

Key Words: telemedicine, policymaking delivery of health care, health services, Philippines

\section{INTRODUCTION}

Corresponding author: Jinky Leilanie $\mathrm{Lu}, \mathrm{MOH}, \mathrm{PhD}$ National Institutes of Health

University of the Philippines Manila

623 Pedro Gil Street, Ermita, Manila 1000, Philippines

Email: jinky_lu@yahoo.com
The World Health Organization (WHO) defines eHealth as the use of information and communication technologies (ICT) for health. ${ }^{1}$ In its broadest sense, eHealth is concerned with improving the flow of information, through electronic means, to support the delivery of health services and the management of health systems. ICT provides significant benefits not only in achieving health goals but 
also in demonstrating what has been attained and at what cost. eHealth has been described to ensure that "the right health information is provided to the right person at the right place and time in a secure, electronic form to optimize the quality and efficiency of health care delivery, research, education, and knowledge." ${ }^{1}$

The advent of ICTs using electronic platforms has indeed changed the healthcare system to reach the greatest number of patients and the farthest areas. Corollary to this are challenges that might hamper or facilitate the improvement of the health system; hence, it is essential to know and understand the basic landscape of this relatively new emerging field in the country.

\section{eHealth - a global perspective}

eHealth, coined in the latter part of the $20^{\text {th }}$ century, refers to the use of ICT, mainly through electronic means, to support the delivery of health services and management of health systems (WHO \& International Telecommunication Union [ITU], 2012). e-Health which can cover all digital health-related information including several components: "1) products, such as instruments to ensure the constant monitoring of blood pressure in ambulatory patients; 2) systems, such as computer-assisted surgery systems; and 3) services, such as a) operating surgical and intensive care units, with interconnected instruments and surveillance services ensuring continuous patient monitoring; b) computerassisted prescription services, where the software checks for incompatible drugs, contraindications, and dosage levels; or c) information services for patients and consumers, including individual electronic health records."

\section{eHealth Benefits for Public Health}

There are various benefits brought about by eHealth in the field of public health. It promotes evidence-based decision-making and patient safety by opening doors for changes in work processes, and improvements in communications, interaction, and risk management. It also helps overcome geographical and time barriers, lessening waiting times and increasing access to health professionals, thereby improving the quality of life of the patients and the general population. In addition to this, eHealth also ensures a heightened efficiency in time and resource use and provides timely data which aids decision-makers in identifying areas to focus on as well as actions that need to be taken to address challenges in the public health arena. ${ }^{3}$

\section{eHealth Key Players}

According to the ITU (2008), the new players in eHealth are grouped accordingly: 1) United Nations agencies and other international bodies dealing with health, telecommunications, and trade; 2) government authorities, health and telecommunication decision-makers at the national and regional levels, as well as the regional bodies to which they belong; 3) academic and research institutions;
4) local health professionals and their associations; 5) consumers, patients and their associations; 6) donors; 7) nongovernmental organizations; 8) the private sector, including foundations and industries related to health and ICTs; and 9) the media.

\section{eHealth Challenges in Southeast Asia}

In the Southeast Asia region, the most important challenge in healthcare is to "reach the unreached" population, given the considerable inequalities currently happening around access to healthcare services. Key challenges in eHealth in the region include the lack of policy and strategy; uncoordinated investment in ICTs in health; low degree of cooperating, collaboration, and sharing across all sectors; limited public sector capacity to implement eHealth programs; widely differing levels of eHealth maturity across and within countries; little or no interoperability and communication of health information systems; poor communication infrastructure; and lack of cooperation between potential stakeholders. ${ }^{3}$

The objectives of the study include 1) to provide a landscape of eHealth in the Philippines since its start in the country; 2) to identify programs, services, and technology innovations implemented in the country on eHealth and telemedicine; and 3) to identify Philippine systems that correspond to the eHealth components laid out by WHOITU for a successful implementation of eHealth at a national level. ${ }^{4,5}$ This study is important as it provides the current landscape and status of eHealth in the Philippines. Hence, policymakers, program implementors as well as other stakeholders including the public will be able to know which eHealth and telemedicine services and products are available in various sectors of society, either private or government, what are the existing gaps in eHealth, and the trajectory in the future based on the guide of the WHO-ITU.

\section{METHODOLOGY}

This study used a narrative qualitative methodology based on secondary data as well as mining of online journals to come up with a comprehensive historical development and evolution of eHealth in the Philippines.

For the assessment of the eHealth in the Philippines, a comprehensive study of the eHealth landscape in the Philippines was conducted through an extensive review of the literature covering research studies, gray literature, peerreviewed journals, databases, and government statistics. The years covered in this study span a total of 24 years from 1997 which marks the beginning of information management systems as an institutional approach in the country to 2020 .

The historical development of eHealth in this study covers the following areas: 1) institutions in the country that have initiated and housed the information technology (IT) systems related to health information, and their 
corollary programs; 2) electronic medical record innovations in the country; 3) devices and technologies connected to EMRs and ICTs for health information and patient data management; 4) the landscape of telemedicine in the Philippines including adoption in hospitals and network institutions; 5) pertinent laws and policies in the Philippines on eHealth and related domains, and 6) appraisal of the state of eHealth in the Philippines using the WHO-ITU framework.

The corresponding protocol for the conduct of this study was cleared and approved by the Research Grant Administration Office of the University of the Philippines Manila.

\section{RESULTS AND DISCUSSION}

Using the context for eHealth development of the WHO-ITU, ${ }^{4}$ the framework used has various components. Leadership and governance consist of activities to direct, implement, and monitor the eHealth goals and outcomes at the national level. Strategy and investment engage stakeholders and sectors through comprehensive strategies and plans. Moreover, legislation, policy, and compliance include the environment for regulating eHealth. The workforce makes the delivery of eHealth attainable through ensuring that knowledge and skills needed are "available through internal expertise, technical cooperation or the private sector." Standards and operability ensure accurate data through interoperability of various systems and to allow data exchange between these channels, and this data exchange is supported by an infrastructure that includes physical infrastructures (network), core services, and applications. These building blocks will strengthen the eHealth strategy. The graphical summary of these components is shown in Appendix 1.

This paper discusses the eHealth landscape in the Philippines using the various components above.

\section{Institutions that have initiated eHealth and their Corresponding Programs}

Specifically, the drivers of the national context for eHealth in the Philippines are four major institutions which are the 1) National Telehealth Center (NTHC) of the National Institutes of Health (NIH), University of the Philippines Manila, 2) Department of Health (DOH) particularly the National Telehealth Service Program (NTSP), a joint project with NTHC, 3) Department of Science and Technology (DOST), and 4) Philippine Research, Education and Government Information Network (PREGINET). The eHealth landscape of these institutions is shown below.

\section{The National Telehealth Center}

The NTHC was established in the University of the Philippines Manila through the University Board of Regents on July 30, 1998. It is now under the NIH of UP Manila, and at the forefront in the conduct of health research and extension services including developing cost-effective tools and innovations in ICT. This is the offshoot of initiatives for telemedicine and eHealth in the NIH in 1997. It also has the telemedicine research-cum-service in remote and underserved areas from Batanes to Zamboanga through partners with the then Commission on Information and Communications Technology's (CICT, 2004-2008) and DOST - Philippine Council for Health Research and Development (DOST-PCHRD, 2008-2011).

The NTHC now has five projects - "1) eLearning - a pre-service and in-service training program to build people's capacities on eHealth; 2) eMedicine - through telemedicine research-cum-service, a patient's condition can be referred directly to clinical specialists in their region or the Philippine General Hospital (PGH) through ICTs; 3) eRecords - advocating electronic medical record systems (EMR) that could easily work with other information systems, an example of this is the Community Health Information Tracking System (CHITS) - the first EMR for governmentbased health facilities now implemented to over 200 health facilities in the country; 4) eHealth Policy and Advocacy; and 5) eSurveillance - innovating mHealth, or the use of mobile technology for health, and web-based systems to monitor performance in reaching goals of $\mathrm{DOH}$ priority programs."

Specific projects and endeavors that have been pursued by NTHC from 2011-2012 are: "1) eLearning and Capacity Building for /via eHealth includes eLearning Videos on tuberculosis, child poisoning, avian flu and stroke implemented in sites of GiveCare Couples for Christ Medical Mission Foundation, and the 1st Philippine Undergraduate eHealth Research Awards; 2) eMedicine covers Telemedicine for DTTB with the DOH, Development of the NTSP in the DOH (Telemedicine component); 3) eRecords includes CHITS such as a) Citywide implementation of CHITS in Quezon City (75 Health Facilities), with the Local Government and collaborative development of additional local and national health program modules; b) Citywide implementation of CHITS in Navotas City (10 Health Facilities) with the WHO - Country Office: collaborative development of additional maternal and child health $(\mathrm{MCH})$ program modules with Navotas Health Office staff; c) Citywide implementation of mCHITS (mobile CHITS) in Navotas City (10 Health Facilities), with the Local Government; d) CHITS Wireless Access for Health Project; e) CHITS implementation in Pasay City, UP Manila MOA with Pasay City - technical support; and f) CHITS implementation in San Juan, Batangas with Health Action Information Network, and training of regional health units (RHU) staff and technical support; 4) eSurveillance covers the NTSP collaborative development of policy, program design and eHealth applications; and 5) eHealth and eHealth policy Advocacy includes medical privacy and patient information confidentiality, in context for eHealth and/or ICTs for Development. ${ }^{6}$ 
Department of Health (DOH) - National Telehealth Service Program (NTSP)

The NTSP is a joint project of the DOH and the NTHC of UP Manila-NIH. It is a 5-year program aimed at expanding telemedicine in $4^{\text {th }}$ to $6^{\text {th }}$ class municipalities nationwide targeting the geographically isolated and disadvantaged areas (GIDAs). NTSP enables consultations between primary care physicians in GIDAs and clinical specialists of the PGH using a mobile and internet-based interface and triaging system.

The NTSP also supports the Doctor-to-the-Barrios program of the $\mathrm{DOH}$, where doctors are assigned to rural and hard-to-reach municipalities. Telehealth services have been offered to more than 350 doctors to the barrios (DTTBs) and municipal health. ${ }^{7}$

The accredited TeleHealth Centers in the Philippines are Baguio General Hospital and Medical Center, PGH, and Eastern Visayas Regional Medical Center. Cordillera Autonomous Region (CAR), Romblon, Masbate, Eastern Visayas, and Tawi-Tawi are the priority NTSP sites. ${ }^{8}$ At present 412 municipal health centers benefiting from this telemedicine service (Table 1 ).

\section{Department of Science and Technology (DOST)}

The DOST has been at the forefront of paving the way for smarter healthcare through the use of ICTs. To date, the projects supported by DOST for smarter healthcare include the RxBox, eHealth Technology-Assisted Boards for LGU Efficiency and Transparency (e-TABLET), and the Philippine Health Information Exchange (PHIE). The projects include 1) RxBox: Connecting medics which was developed by the University of the Philippines ManilaNTHC and DOST. The RxBox is a medical device with built-in medical sensors for monitoring blood pressure and blood oxygen levels, assessing the strength of contraction of the mother's uterus, electrocardiogram, and fetal heart monitor. The data acquired by the sensors can easily be stored and transmitted to a specialist in urban areas for further consultation and management; 2) e-TABLET: Managing medical records - the e-TABLET is a tablet-based electronic medical record system developed by Ateneo de Manila's Institute of Philippine Culture and Ateneo Java Wireless and Competency Center. It is a system that enables health

Table 1. Summary of telemedicine sites per region $(\mathrm{N}=416)$

\begin{tabular}{ccccc} 
Region & Number of sites & & Region & Number of sites \\
CAR & 54 & & Region VII & 14 \\
Region I & 16 & & Region VIII & 136 \\
Region II & 14 & & Region IX & 15 \\
Region III & 7 & & Region X & 19 \\
Region IV-A & 110 & & Region XI & 5 \\
Region IV-B & 32 & & Region XII & 3 \\
Region V & 29 & & Region XIII & 19 \\
Region VI & 20 & & ARMM & 23 \\
\hline
\end{tabular}

Adapted from National Telehealth Service Program Infographics, $2015^{8}$ workers to encode and manage patient information; 3) PHIE: Centralized medical records - The PHIE is a centralized database of health and medical records nationwide that enables a patient to retrieve personal medical records. This allows sharing of patient records among hospitals for accurate and timely health information; 4.) Internet connectivity is essential in providing eHealth. In line with this, the DOST through its Information and Communication Technology Office is tapping into the potential of TV White Spaces, or unused frequencies between broadcast TV channels, to service cost-effective internet connectivity and data delivery in areas underserved by private providers. ${ }^{9}$

\section{Philippine Research, Education and Government Information Network (PREGINET)}

PREGINET is a research and education network (REN) in the Philippines. It is under the Advanced Science and Technology Institute, a research and development agency attached to the DOST.It also has a network with international RENs such as the TEIN and Asia-Pacific Advanced Network, Trans-Eurasia Information Network 3 (TEIN3), School-onthe-Internet Asia, and Collaboration for Network-enabled education Culture, Technology and Science (CONNECT) Asia. PREGINET conducted the First Philippine Telemedicine Network Symposium in 2016 participated by St. Luke's Medical Center, PGH, National Kidney and Transplant Institute, Baguio General Hospital, University of Cebu Medical Center, Davao Doctors Hospital, Aborlan Medical Care, and the Veterans Memorial Medical Center. PREGINET provides services such as voice over IP (VoIP), videoconferencing, and technical consultancy, among others. It also supports e-learning activities and telemedicine in the Philippines thru its veritable collaboration with the NTHC, UP-PGH, Manila Doctors Hospital (MDH), and Veterans Memorial Medical Center (VMMC). Its regular technical support to said hospitals during live surgical demonstrations has been an important strategy in e-learning in the medical field. ${ }^{10}$

The comparison of the abovementioned eHealth drivers in the Philippines is summarized in Table 2.

\section{Electronic Medical Records in the Country}

Paper-based medical record systems pose problems with errors, destruction, or alterations in records. There is also the problem of consolidating paper-based data into a cohesive and consolidated report. ${ }^{11}$ Thus, the need for electronic medical record systems that provide real-time access and monitoring of patients' conditions. This also improves workflow as it decreases the time to pull out charts by allowing remote access, and provides access to convenient appointment scheduling, prescription, and management. ${ }^{11}$ Likewise, EMRs serves as a major communication tool for physicians and other allied healthcare workers, thus health providers become better informed. ${ }^{12}$ The consolidated electronic data can also be used for decision-making 
Table 2. Comparison of eHealth drivers in the Philippines

\begin{tabular}{lcccc}
\multicolumn{1}{c}{ Components } & $\begin{array}{c}\text { National Telehealth } \\
\text { Center }\end{array}$ & $\begin{array}{c}\text { National TeleHealth } \\
\text { Service Program }\end{array}$ & $\begin{array}{c}\text { Department of Science } \\
\text { and Technology }\end{array}$ & $\begin{array}{c}\text { Philippine Research, Education and } \\
\text { Government Information Network }\end{array}$ \\
\hline TeleMedicine & Yes & No & No & Supporting Platform \\
Managing medical records & Yes & Yes & Yes & No \\
Tracking & Yes & Yes (during pandemic) & Yes & No \\
Policy and Advocacy & Yes & No & Ongoing & Supporting Platform \\
Surveillance & Yes & Yes (during pandemic) & Yes & No \\
eHealth Technology & No & No & Yes & No \\
\hline
\end{tabular}

regarding medical interventions. ${ }^{13}$ In the Philippines, several EMRs have been developed by different concerned agencies, hospitals, and the academe. The more prominent are: CHITS of the University of the Philippines Manila; Integrated Clinic Information System (iClinicSys) of the DOH; and SHINE OS+ of Ateneo University.

iClinicSys was developed by the $\mathrm{DOH}$ which provides public health information systems targeting local health units (e.g., health centers, rural health units, and barangay health stations). In general, the data collected from iClinicSys such as demographics, consultations, health services availed (e.g., immunization, maternal care, family planning,), laboratory examinations, diagnosis, and other clinical health data are processed and uploaded to the DOH electronic Field Health Services Information System system. ${ }^{14}$

Similar to the target demographics of iClinicSys, SHINE OS+ (Secured Health Information Network and Exchange) was developed by Smart Communications and the Ateneo Java Wireless Competency Center for information recoding, appointment and medicine reminders through text messages to patients, faster referral, and summarizing health information reports to $\mathrm{DOH}$ and PhilHealth "for faster processing of e-claims and real-time health statistics." ${ }^{15} \mathrm{~A}$ recent development for SHINE OS+ is its offline version which allows monitoring and tracking even with limited internet connection access. ${ }^{16}$

CHITS was developed by the NTHC of the University of the Philippines Manila to aid in the management of health data in the RHU level. ${ }^{17}$ CHITS aids in the efficient patient record encoding and retrieval which can be generated upon patient admission. Requests for pertinent clinical data such as laboratory results and reports can also be uploaded through CHITS. Moreover, CHITS is connected to the RxBox, a mobile health device and developed by the University of the Philippines Manila as well, to can measure the patient's vital statistics. As of 2020, CHITS is currently being utilized in 35 RHUs all over the Philippines, 33 public health centers in Taguig City, 12 in Pasay City, and 91 in Quezon City. ${ }^{11}$

Aside from these, the DOH validates EMRs by thirdparty providers that can be used for patient information recording (Table 3).

Table 3. List of validated EMRs for hospital statistics

\begin{tabular}{lcc}
\hline \multicolumn{1}{c}{ System Name } & Company Name & Date Validated \\
\hline Third Party Providers & & \\
\hline iHomis & DOH & 2019 \\
Comlogik & New Comlogik Business System & September 16, 2019 \\
Medix & E-Med Health Care Solutions Inc. & October 1. 2019 \\
Bizbox Hospital Systems & Bizbox Incorporated & October 21, 2019 \\
Cerebro HIS & Cerebro Diagnostic System & November 22, 2019 \\
Drainwiz & Drainwiz Computer System & December 5, 2019 \\
MakMed EMR & Makilala Medical Hospital Inc. & December 20, 2019 \\
Simple HIS & Simple Softech Solutions Co. & January 3, 2020 \\
Medsys & KCCl - Medsys & January 16, 2020 \\
Magis Hospital Information System & MMG Federation & January 16, 2020 \\
Hospital One & Hospital One & January 16, 2020 \\
MeRx & Medcurial & February 28, 2020 \\
Diana HIS & Geodata & March 9, 2020 \\
Appoluz & CNR Software Systems & March 12, 2020 \\
Seg HIS & & November 3, 2020 \\
\hline In-House Developed & & \\
\hline St. James Hospital Inc & & March 9, 2020 \\
Divine Mercy Hospital & Segworks Technology Corporation & March 9, 2020 \\
Family Care Hospital & March 9, 2020 \\
\hline Adapted from Department of Health - National eHealth Electronic Health Records System Validation, n.d.18
\end{tabular}


mHealth Devices and Technologies for Health Information and Patient Data Management in the Philippines

To improve access to care and quality of healthcare, there are two main technological projects of the NTHC, in collaboration with the DOH, DOST, the RxBox and the Real-time Monitoring of Vital Maternal and Child Health Indicators (rCHITS).

\section{The RxBox}

The $\mathrm{RxBox}$ is a machine capable of measuring vital signs (heart rate, ECG, blood pressure, pulse rate and oxygenation) and transmit this data through both the Internet and GSM network to a medical specialist in a different location.

The RxBox is a multi-component program (biomedical device, electronic medical record system, and telemedicine training) designed to provide better access to life-saving health care services in isolated and disadvantaged communities nationwide. It is also an ICT innovation designed to support the DOH's call for "Kalusugang Pangkalahatan" or Universal Health Care (UHC).

The RxBox is a telemedicine device capable of capturing medical signals through built-in medical sensors, storing data in an electronic medical record (Community Health Information Tracking System - CHITS), and transmitting health information via the internet to a clinical specialist in the PGH for expert advice. It also catalyzes improvement in the local referral system by facilitating teleconsultations (audio-video conferences) within the NTSP. The RxBox can reduce the overall cost of healthcare by enabling health workers to diagnose, monitor, and treat patients within the rural health facility, thanks to medical sensors inside the box. ${ }^{19}$

In 2017, there are 169 RxBox units deployed in different municipalities and cities (Appendix 2).

The height of the COVID-19 pandemic prompted the deployment of additional 369 units of RxBox in different regions of the country in 2020 (Appendix 3). ${ }^{20}$

\section{The rCHITS}

On the other hand, rCHITS through CHITS was developed to strengthen the health information systems of health facilities across the country through the use of ICTs. rCHITS has the following components - the use of 1) EMR CHITS; 2) mReports, an android-based application reporting system for rural health midwives to document and transmit clinical data through smartphones; and 3) an LGU dashboard, a visualization tool that facilitates analysis of health data and decision-making. mReports, one of the main components of rCHITS, focuses on equipping field health workers with the capacity to report maternal and child health services rendered, create appointments for, and send reminders to patients on maternal and child-care services in real-time using mobile phone and SMS Technology.

From November 2011 to August 2016, rCHITS was implemented in 13 selected GIDAs with high rates of maternal mortality and poverty incidence. A total of 365 health workers nationwide were also trained in using rCHITS during the duration of the project. Its implementation was made possible through the support of the UNICEF Joint Programme on Maternal and Neonatal Health (JPMNH).

MInTS (Mag-Ina Telereferral System) and BiRTS (Birth Registration Tracking System) are part of rCHITS Quezon City component or rCHITS supported by the JPMNH. MInTS aims to strengthen the service delivery network of maternal and neonatal referral and feedback process between health facilities. Meanwhile, the BiRTS facilitates birth registration through the digital form from rCHITS to the Local Civil Registry (LCR). As of February 2016, 277 health workers from District 2 Health Center and Lying-In clinics, along with partner hospitals implementing MInTS (QMMC \& QCGH) were trained on MInTS. ${ }^{21}$

\section{Telemedicine Services in Philippine Hospitals}

Telemedicine generally refers to the use of communications and information technologies for the delivery of clinical care over the cellular phone/telephone or use of satellite technology and videoconferencing to conduct realtime consultation and medical care across distance in the interface between patient and doctor, among doctors with specialists, and between and among various hospitals locally and internationally. This may include diagnostic testing or monitoring a patient's posttreatment progress in any specialty such as cardiology, dermatology, and ever emergency medicine. ${ }^{22}$ It is also defined as the practice of health care delivery, diagnosis, consultation, treatment, transfer of medical data, and education using interactive audio, visual, and data communications. ${ }^{23}$

Telehealth is an expansion of telemedicine, and unlike telemedicine (which more narrowly focuses on the curative aspect), it encompasses preventive, promotive, and curative aspects. Telehealth involves a broader variety of clinical and nonclinical remote healthcare services such as patient education, assistance with medication adherence, and troubleshooting of health issues. ${ }^{24}$ Telehealth is defined as the use of electronic information and telecommunications technologies to support long-distance clinical health care, patient and professional health-related education, public health, and health administration. ${ }^{25}$ Telehealth can be applied to different settings including primary and long-term care, mental health, and even school health. ${ }^{26}$

With telemedicine, remote communities have access to the services of clinical specialists in their region and the PGH. Health data reported through R4Health in real-time assists decision makers manage resources, allocate funds, plan and budget investments on health which can translate to better health for Filipinos. To date, telehealth services have been offered to more than 350 DTTBs and municipal health officers through various government initiatives of the $\mathrm{DOH}$ and the NTSP. ${ }^{8}$ There are 412 municipal health centers benefiting from this telemedicine service. ${ }^{25-27}$ 
Telemedicine services have also been offered by major hospitals in the Philippines as they foresee its importance to their clientele. This shows the wide penetration of eHealth services and telemedicine not only to target the poor, but also in giving faster, more efficient, and equally effective virtual health services to the public, even the private-pay patients. ${ }^{28}$

Telemedicine services in the Philippines include teledermatology, teleparasitology, telesurgery, teleaudiology, teleradiology, teleophthalmology, telepsychiatry, telepharmacy, and telecardiology. All these revolve around the use of technologies in delivering efficient and convenient healthcare services to patients.

Teledermatology started as part of the design for Community teleservice, together with geotelemedicine and teleradiology, in the program of the National Academy of Science and Technology in 2002. Teledermatology using mobile phones was shown to reach underserved communities that have a scarcity of dermatologists. ${ }^{26}$ This is being implemented in PGH. Teledermatology is seen as an accurate diagnostic tool of dermatologic conditions relative to the face-to-face medical consultation, and that health care providers are open to such a new form of consultation. ${ }^{27}$ There are two additional providers of teleradiology in the Philippines: Lifetrack Medical Systems (LMS) and Mediaarchives Philippines Inc. (MAPI). LMS features a radiology software platform that is paired with experienced radiologists in hospitals who help evaluate medical images. MAPI has a virtual clinic where radiologic images such as X-rays, CT scans, and MRIs are transmitted from one location to another to share studies with other radiologists and physicians. ${ }^{29}$

On the other hand, telesurgery and telecardiology of The Medical City (TMC) use robotic systems to aid in procedures related surgeries. TMC has pioneered in robotic-assisted surgery telecardiology as well as stem cell therapy and regenerative medicine, leukemia and lymphoma management, customized wellness, and liver transplantation. The Ortigas hospital serves as a hub for 17 satellite outpatient clinics and 4 other hospitals in the provinces and Guam. ${ }^{30}$

JR Borja General Hospital, a hospital in Cagayan de Oro City, is the first to launch the Telepsychiatry Project in 2016 which was aimed at giving medical/clinical diagnoses and prescriptions to mentally ill patients in Cagayan de Oro City and neighboring provinces through video conferencing. This was in partnership with the Southern Philippines Medical Center in Davao City. ${ }^{31,32}$

Telepharmacy is generally used to prescribe medications online. Telepharmacy Services is also covered by Republic Act No. 10918 otherwise known as the Philippine Pharmacy Act which ensures the availability of prescription drugs via telephony among the 1,069 GIDAs in the country. ${ }^{33}$ Telepharmacy is envisioned to provide solutions to the pharmacy staffing woes in the Philippines as it provides instantly available relief pharmacists on a short- or longterm basis as well as remote supervision of rural pharmacies.
Teleophthalmology assists in eye examinations. The Philippine Eye Research Institute of the NIH has established the Teleophthalmology Retina Reading Center in the Philippines. This is in collaboration with the Harvard Medical School and the Joslin Diabetes Center to establish. The program provides diagnostic services through fluorescent angiography and optical coherence tomography of the retina. ${ }^{34}$ TMC operates the first and only teleophthalmology clinic in the Philippines, where digitized eye examination images captured from across the TMC health network both locally and internationally are transmitted online to the Eye Center and interpreted by experts of each eye sub-specialty. ${ }^{31,35}$ Another endeavor was a study on the implementation and pilot data on diabetic retinopathy in a teleophthalmology program at a multispecialty primary care clinic. This program has facilitated early detection of potentially sight-threatening disease thus preventing visual loss and other complications. ${ }^{35}$

Teleparasitology connects experts via online microscope/ mobile phone interface for early and accurate diagnosis of various parasitic diseases which is in response to the challenge of the WHO to strengthen expertise and information systems to overcome the global impact of neglected tropical diseases which affect about 42 million at-risk individuals globally. In the Philippines, millions of Filipinos are suffering from four major neglected parasitic infections, namely, schistosomiasis, lymphatic filariasis, and food-borne trematode infections in 44 endemic provinces. ${ }^{36}$ Most peripheral laboratories lack the expertise and technology for accurate and early diagnosis of emerging and re-emerging parasitic infections. Hence, the Philippine Health Research Registry implemented a project called "Medical Teleparasitology for Laboratory Diagnosis of Parasitic Infections in the Philippines," to connect peripheral laboratories to selected regional diagnostic referral centers. ${ }^{37}$ In 2014, the Philippine project on controlling parasitic diseases, called the ctrl.para.site - was implemented to link peripheral laboratories to experts via an online microscope/ mobile phone interface for early and accurate diagnosis of various parasitic diseases. The ctrl.para.site project targeted laboratory staff in two regions in the country - Western Visayas and CARAGA.

Teleaudiology, on the other hand, was set to realize the Universal Newborn Hearing Screening and Intervention Act for mandatory hearing screening of newborns in the Philippines. ${ }^{38}$ Teleaudiology is seen as vital a means for GIDAs to comply with the requirement of the Universal Newborn Hearing Screening and Intervention Act, that all newborns must be screened for hearing loss within 3 months after birth. The newborn hearing screening device with telehealth capabilities will enable all newborns to be screened by accredited screening centers without traveling great distances. The telehealth capability involves the deployment of automated data collection for local (CHITS/EMR) and cloud storage (NHS Registry), and through the tele- 
audiology protocol, facilitate prompt referral for confirmatory testing and intervention. The project also incorporates capacity building among primary care health facilities (telelearning) for newborn hearing screening to screen and appropriately refer patients with potential congenital hearing problems. ${ }^{38}$

\section{Telemedicine in Local Government Units}

The height of the COVID-19 pandemic has opened opportunities for telemedicine to flourish in the Philippines. Hospitals and LGUs sought alternatives or supplements to the traditional face-to-face consultations to adapt to the new normal. In the National Capital Region, telemedicine services are being offered to COVID-19 and non-COVID-19 patients for free through telemedicine hotlines launched by the $\mathrm{DOH}$ in partnership with private companies: Telimed Management Inc. and Medgate. ${ }^{39}$ In the CALABARZON region, "O-HI DOC" (Oral Health Initiative for Dental Online Consultation) project by DOH-CALABARZON allowed consultations and referral systems via mobile phones or telephones to address dental issues of patients especially those in the GIDAs in response to COVID-19 pandemic. ${ }^{40}$

LGU initiatives also adapted to telemedicine. In Davao City, in the southern part of the Philippines, Davao Central 911 set up consultations remotely using telemedicine to minimize personal contacts between healthcare workers and patients. This expanded through Executive Order (EO) 20 authorizing doctors to prescribe medicines remotely through a text message from $911 .{ }^{41}$ Telepsychology is also being offered free in Davao through their HOPE line. ${ }^{41}$ Taguig in Metro Manila also set up telemedicine hotlines to serve as a communication platform for healthcare professionals and patients remotely. ${ }^{42}$ This may be done through traditional text messages or online through an application that allows video calls via cellphones. Moreover, health workers also deliver prescriptions and/or health services such as immunizations done house-to-house. ${ }^{43}$

Telemedicine in the city of Quezon City in Metro Manila is COVID-19 patient-focused. The LGU set up an online system called Quezon City COVID Telemed Program wherein patients who are COVID-19 positive isolating in their homes or quarantine facilities can consult with their doctors online ${ }^{44}$ via video calls. Online prescriptions are also e-mailed to the patients. ${ }^{45}$ This initiative is in partnership with the $\mathrm{DOH}$ and is "connected directly to the national COVID-19 surveillance system" in the Philippines. ${ }^{46}$

\section{Telemedicine in Other Countries}

Telemedicine was established primarily to meet the healthcare demands of an aging population and accommodating the increasing burden of non-communicable diseases. ${ }^{47}$ This bridges the gap in healthcare professionals, specialists, and caregivers' shortages, and most importantly in providing access to where there was previously none or there was an increasing demand in the overall level of care.
Telemedicine in various countries involves delivering healthcare services in different departments. In the United States (US), telehealthcare services have become popular. ${ }^{48}$ It is widely used in radiology, psychiatry, and cardiology. ${ }^{49}$ In 2016, 50\% of the 110 million recorded patient visits were conducted online based on Kaiser Permanente, which is the integrated largest health network in the US. A study showed that patients were more satisfied with the services offered by telemedicine with lesser misdiagnoses and lower malpractice complaints. ${ }^{50}$

In Canada, technologies to deliver health care virtually such as telemedicine/telehealth, have been around for decades $^{51,52}$ and the main driver for advancing telehealth is to meet healthcare demands conveniently and on time. Advances on Canadian physician's offices and healthcare facilities now use some form of a digital record, but there is still a long way to go in terms of the use of digital technology to provide in-depth virtual care. ${ }^{51}$

Telehealth in Australia, on the other hand, was ideally placed to support major national programs associated with dementia, mental health, diabetes, and regional concerns related to rehabilitation, acute waiting list relief, and outpatient support. Other purposes of telehealth are also for non-clinical use to which the latter is being utilized for education, case study analysis, peer review, and networking, health promotion, mentoring and supervision, research and evaluation, and rural and urban support. ${ }^{53}$

In Indonesia, the development of telemedicine started during the 1980s to solve shortages in healthcare workers. In the 2000s, the rise of signal speed eligible for audio and video transfer facilitated teleconsultations of radiology and cardiologic cases. In general, the objectives of telehealth/ teleradiology in Indonesia were to give expert services to several hospitals/ community health centers that do not have any radiologist/cardiologist to interpret radiological images of ECG with the additional project for tele-ECG. In recent years, with the use of online health service applications such as Halodokter.com, Konsula.com, and Halodok, patients can contact medical professionals online and access their medical conditions online. ${ }^{54}$

In Malaysia, telehealth aims to strengthen the delivery of healthcare through the use of technologies. The Telemedicine Act of 1997 is the regulating and controlling body of the telemedicine industry in Malaysia, and it is the only country with specific laws for telehealth in South East Asia. ${ }^{55}$ India also has telemedicine projects such as Apollo, Otri, and Asia Heart Foundation which focus on the delivery of cardiology, emergency, radiology, ophthalmology, and nephrology healthcare needs. ${ }^{56}$

\section{Laws and Policies on eHealth in the Philippines}

The various laws, policies, and programs on and related to eHealth in the Philippines in this study are summarized in Table 4. 
Table 4. Summary of eHealth Policy Domains and Relevant Policies and Programs in the Philippines

\begin{tabular}{|c|c|}
\hline Policy Domain & Relevant Policies/Programs \\
\hline $\begin{array}{l}\text { Networked } \\
\text { Care }\end{array}$ & $\begin{array}{l}\text { - DOH Information Systems Strategic Plan (ISSP) } \\
\text { 2011-2013 } \\
\text { - RA 10173: Data Privacy Act of } 2012 \\
\text { - RA 9995:Anti-Photo and Video Voyeurism Act } \\
\text { of } 2009\end{array}$ \\
\hline $\begin{array}{l}\text { Inter- } \\
\text { jurisdictional } \\
\text { Practice }\end{array}$ & $\begin{array}{l}\text { - RA 2382: The Medical Act of } 1959 \\
\text { - RA 7392: Philippine Midwifery Act of } 1992 \\
\text { - RA 5181: Act prescribing permanent residence } \\
\text { and reciprocity as qualifications for any } \\
\text { examination or registration for the practice of } \\
\text { any profession in the Philippines } \\
\text { - RA 7164: Philippine Nursing Act of } 1991 \\
\text { - RA 8344: Hospital Doctors to treat emergency } \\
\text { cases referred for treatment } \\
\text { - AO 114: Revised/updated the roles and } \\
\text { functions of the Municipal Health Officers, } \\
\text { Public Health Nurses and Rural Midwives } \\
\text { - PMA, Medical Society by-laws }\end{array}$ \\
\hline $\begin{array}{l}\text { Diffusion } \\
\text { of eHealth } \\
\text { Addressing the } \\
\text { Digital Divide }\end{array}$ & $\begin{array}{l}\text { - Free and Open Source Software (FOSS) } \\
\text { - Community e-Centers (CeCs) } \\
\text { - DepEd: Gearing up Internet Literacy and Access } \\
\text { for Students (GILAS) } \\
\text { - DOH: Universal Health Care (UHC) }\end{array}$ \\
\hline $\begin{array}{l}\text { Integration } \\
\text { into Existing } \\
\text { Systems }\end{array}$ & $\begin{array}{l}\text { - DOH EA, ISSP } \\
\text { - Philippine Government Interoperability } \\
\text { - Framework (PGIF) Advocacy } \\
\text { - ICT4H: Standards and Interoperability } \\
\end{array}$ \\
\hline $\begin{array}{l}\text { Handling } \\
\text { Innovation at } \\
\text { Different Levels }\end{array}$ & $\begin{array}{l}\text { - RA 8792: E-commerce Act } \\
\text { - DOH: UHC } \\
\text { - EO 269: Creating the Commission on } \\
\text { Information and Communications Technology }\end{array}$ \\
\hline $\begin{array}{l}\text { Policy Goal } \\
\text { Setting }\end{array}$ & $\begin{array}{l}\text { - DOH: UHC, EA, ISSP, National eHealth Strategic } \\
\text { Framework } \\
\text { - ICT4H: Standards and Interoperability } \\
\text { - RA 8792: E-commerce Act }\end{array}$ \\
\hline $\begin{array}{l}\text { Evaluation and } \\
\text { Research }\end{array}$ & $\begin{array}{l}\text { - Philippine Health Research Act of } 2008 \\
\text { (University of the Philippines NIH, NTHC) }\end{array}$ \\
\hline Investment & $\begin{array}{l}\text { - RA 8792: E-Commerce Act } \\
\text { - Philippine Health Insurance Corporation (PHIC) } \\
\text { - policies on financing health workers working in } \\
\text { remote areas, Primary Care Benefit packages }\end{array}$ \\
\hline Ethical Issues & $\begin{array}{l}\text { - Philippine Medical Association Code of ethics } \\
\text { - RA } 6713 \text { - Code of Conduct and Ethical } \\
\text { Standards for Public Officials and Employees }\end{array}$ \\
\hline
\end{tabular}

\section{Way Forward and Trajectory of eHealth in the Philippines}

Using the WHO-ITU (2012) ${ }^{4}$ eHealth components, the assessment of national government agencies and stakeholders are shown below.

For leadership and governance, the government and academic sectors are the major players. Based on the landscaping of the eHealth environment provided in this paper, these institutions include the NTHC-University of the Philippines Manila, DOH, PCHRD, DOST, among others.

For services and applications, the involved stakeholders are the EMR providers, telehealth and telemedicine providers and practitioners, mHealth technology innovators and developers, and others. This aspect also includes the local government units that provide primary health care and various hospitals engaged in eHealth services and telemedicine.

For standards and interoperability, the academic community and the government are essential players. The academe can feed evidence-based research for standards and interoperability while the national government agencies can establish and implement standards of eHealth and the interoperability of systems. The EMR providers are to be engaged in this component to ensure the interoperability of systems. There should also be standards for the ethical practice of eHealth practice and eHealth research. In eHealth practice, this includes standards and quality of care, data protection, the duty of care, management plan for treatment, privacy and confidentiality, safeguard against medical malpractice, vulnerability and risks, and accountability to patient care. In eHealth research, standards on the following are needed- medical devices, disclosure of research results, informed consent, beneficence and non-maleficence (nonmalfeasance), participation of groups that require special consideration, disclosure of research results, among others. Likewise, there is a need to come up with standards and guidelines for the assessment and licensing of eHealth technologies, medical devices, and medical equipment. eHealth regulation in this respect ensures safety and efficacy of device, clinical and cost-effectiveness, prevention of harm among users and beneficiaries, safeguarding technology life cycle, and benefits to the entire community.

Legislation, policy, and compliance come hand in hand with standards-setting. An overall eHealth policy must be legislated. This puts forward the following essentials of eHealth; the implementing rules and regulations; the functions, mandate, accountability, and resources of respective government agencies and officials; and infrastructure to enable the implementation of eHealth.

In the aspect of infrastructure, both the internal and external support infrastructure is targeted. Internal infrastructure includes the eHealth system including interoperability. The external infrastructure that supports the viability of eHealth includes good electrification and wide internet coverage.

The workforce includes both health and non-health practitioners and employees. There are the health professionals, health providers and caregivers, health researchers, academics, and employees of health organizations and institutions. There are also hardware and software providers, health informatics professionals, and outsourced business enterprises.

The National eHealth Strategy in the Philippines has been put forward and is currently being used as a guide for the implementation of eHealth in the country. However, it is still in its incipient stage and being discussed by the National eHealth Steering Committee composed of important national agencies and institutions.

As shown in this study, the Philippines has started to build an enabling environment for eHealth through 
telemedicine services and the use of mHealth devices to facilitate access to care and improving the quality of that care. However, a national plan in this context should focus on making the case for eHealth, through setting up of an institutional structure at the governance level with oversight from the national government itself, creating sustainable enabling environment through the passing of eHealth bills, government funding and not merely project-based contracts, and building workforce education both at the tertiary level and continuing specialty education. The adoption of a national eHealth strategy is also mandatory. These are referred to as enabling environments that should complement the growing and expanding ICT environment. ${ }^{4}$

The study merely covered internet sources which can also be considered as a rigorous tool in analyzing data. This presents as a limitation. It is recommended that interviews and data collection be gathered from concerned agencies to validate or complement the results of this study.

\section{CONCLUSION}

The incorporation of eHealth in healthcare services is essential in providing UHC and health services to the underserved populations who are usually located in geographically isolated and resource-poor areas. The study has shown the following: 1) the major institutions that initiated eHealth in the country including their programs and initiatives; 2) the various electronic medical record platforms existing in the country; 3) the mHealth devices that have been innovated to facilitate eHealth and telemedicine; 4) the various telemedicine services implemented by both hospitals and local government units as a mechanism for service delivery network, including covid coverage; 6) laws and policies on and related to eHealth and telemedicine that serve as support for policies and programs; and 7) appraisal of eHealth landscape using the WHO-ITU framework on eHealth. The study has shown that the context for eHealth development in the Philippines is still in the initial stages of development. There are already several efforts to make eHealth palpable in healthcare delivery and health information system; however, these are not yet sustained on a long-term basis, and are merely project-based, and donordriven. A sustainable eHealth program in the Philippines requires a national effort to institutionalize an eHealth system with components that are interrelated and seamless. It is also noteworthy to mention through the review of literature that the Philippines has already gained momentum in various components of eHealth covering leadership and governance, services and applications, standards and interoperability, infrastructure, legislation, policy and compliance, and workforce.

\section{Statement of Authorship}

Both authors participated in the data collection and analysis and approved the final version submitted.

\section{Author Disclosure}

Both authors declared no conflicts of interest.

\section{Funding Source}

This study was funded by the National Telehealth Center, National Institutes of Health, University of the Philippines Manila.

\section{REFERENCES}

1. World Health Organization, Building foundations for eHealth: progress of Member States: report of the WHO Global Observatory for eHealth [Internet]. 2006 [cited 2021 Mar]. Available from: www.who.int/goe/publications.

2. International Telecommunication Union (ITU). Implementing e-health in developing countries: Guidance and principles [Internet]. 2008 [cited $2021 \mathrm{Mar}$. Available from https://www.itu.int/ITU-D/ cyb/app/docs/e-Health_prefinal_15092008.PDF.

3. World Health Organization, WHO global strategy on peoplecentered and integrated health services: interim report [Internet]. 2015 [cited $2021 \mathrm{Mar}$. Available from: https://www.who.int/service deliverysafety/areas/people-centred-care/global-strategy/en/

4. World Health Organization, International Telecommunication Union. National eHealth Strategy Toolkit. World Health Assembly Resolution and ITU World Telecom Development Conference Resolution. 2012 [cited $2021 \mathrm{Mar}$. Available from: http://www.itu.int/pub/D-STR-E_ HEALTH.05-2012.

5. Khoja S, Durrani H, Nayani P, Fahim A. Scope of policy issues in eHealth: results from a structured literature review.J Med Internet Res. 2012 Feb 17; 14(1):e34. doi: 10.2196/jmir.1633. PMID: 22343270; PMCID: PMC3374525.

6. National Telehealth Center [Internet]. Manila: University of the Philippines Manila; c2021 [cited 2021 Feb]. Available from: https://telehealth.ph/

7. Fernandez-Marcelo PG, Ho BL, Faustorilla Jr. JF, Evangelista AL, Pedrena M, Marcelo A. Emerging eHealth Directions in the Philippines. Yearb Med Inform. 2012; 7:144-52.

8. National Telehealth Center. National Telehealth Service Program [Internet]. 2015 [cited $2021 \mathrm{Mar}$ ]. Available from: https://telehealth. $\mathrm{ph} /$ project-ntsp/

9. Department of Science and Technology. DOST PUSHES EHEALTH TECHNOLOGIES FOR SMARTER HEALTHCARE [Internet]. 2014 Feb 20 [cited 2021 Jan]. Available from : https://www.dost.gov. ph/index.php/knowledge-resources/news/34-2014-news/39-dostpushes-ehealth-technologies-for-smarter-healthcare

10. Babaran K.PH healthcare facilities shift gears to telemedicine through PREGINET [Internet]. 2016 Aug 2 [cited 2021 Jan]. Available from: http://pregi.net/uncategorized/ph-healthcare-facilities-shift-gearsto-telemedicine-through-preginet/

11. Ongkeko AM. Community Health Information Tracking System (CHITS) [Internet]. 2020 May 28 [cited 2021 Mar]. Available from: https://www.pchrd.dost.gov.ph/programs-and-services/createarticle/6556-community-health-information-tracking-system-chits.

12. Manca DP. Do electronic medical records improve quality of care? Yes. Can Fam Physician. 2015 Oct; 61(10):846-7.

13. Department of Health, Philippine Health Insurance Corporation, Department of Science and Technology, Department of Information and Communications Technology. Joint Administrative Order No. 2017-0001 [Internet]. $2017 \mathrm{Jul} 26$ [cited $2021 \mathrm{Mar}$ ]. Available from: http://ehealth.doh.gov.ph/index.php?option=com_content\&view= category\&layout=blog\&id $=87$

14. Department of Health Zamboanga Peninsula - Center for Health Development. INTEGRATED CLINIC INFORMATION SYSTEM (ICLINICSYS) [Internet].n.d. [cited $2021 \mathrm{Mar}$. Available from: https://ro9.doh.gov.ph/index.php/health-info-systems/ philgeps-online-2 
15. International Public Relations Association. SHINE OS+ or Secured Health Information Network and Exchange PDF [Internet]. n.d. [cited $2021 \mathrm{Mar}$ ]. Available from: https://www.ipra.org/shop/product/ shine-os-or-secured-health-information-network-and-exchangepdf/\#: :text=SHINE\%20OS\%2B\%20or\%20Secured\%20Health\%20 Information\%20Network\%20and\%20Exchange\%20is,facilities\%20 in\%20the\%20developing\%20country.

16. Sun Star. Healthcare gets boost through Shine OS+ [Internet]. 2017 Aug 24 [cited $2021 \mathrm{Mar}$. Available from: https://www.sunstar.com. $\mathrm{ph} /$ article/160362/Business/Healthcare-gets-boost-through-SHINEOS\%20-.

17. National Telehealth Center. CHITS [Internet]. n.d. [cited 2021 Mar]. Available from: https://telehealth.ph/project-chits/

18. Department of Health - National eHealth Electronic Health Records System Validation. List of Validated EMRs for Hospital Statistics [Internet]. n.d. [cited $2021 \mathrm{Mar}$. Available from: http://ehealth. doh.gov.ph/nehehrsv/index.php/validated-emr-s.

19. RxBox [Internet]. Manila: University of the Philippines Manila; c2021 [cited $2021 \mathrm{Mar}$ ]. Available from: https://rxbox.chits.ph/

20. Philippine Council for Health Research and Development. Health research in the time of a pandemic: Annual Report 2020. 2021 Mar 17 [cited $2021 \mathrm{Apr}$ ]. Available from: https://www.pchrd.dost.gov.ph/ phocadownload/2020\%20PCHRD\%20ANNUAL\%20REPORT.pdf

21. National TeleHealth Center, What's Hot on eHealth: rCHITS conducts MInTS, BiRTS Training, caters QC health workers [Internet]. 2016 Feb 17 [cited $2021 \mathrm{Mar}$. Available from: https:// telehealth.ph/2016/02/17/whats-hot-on-ehealth-rchits-conductsmints-birts-training-caters-qc-health-workers/.

22. Nelson R. Telemedicine and Telehealth: The Potential to Improve Rural Access to Care. Am J Nurs. 2017 Jun; 117(6):17-18.

23. Kansas Telemedicine Policy Group. The Role of Telemedicine in Health Care Delivery. Vol. 1. Topeka, Kan: Kansas Department of Health and Environment; 1993 Nov. Telemedicine: Assessing the Kansas Environment.

24. Schlachta-Fairchild L, Elfrink V, Deickman A. Patient Safety, Telenursing, and Telehealth [Internet]. In: Hughes RG, editor. Patient Safety and Quality: An Evidence-Based Handbook for Nurses. Rockville (MD): Agency for Healthcare Research and Quality (US); 2008 Apr. pp 135-74. Available from: https://www.ncbi.nlm.nih. gov/books/NBK2687/.

25. Igna HJ. INFOGRAPHIC: How does telemedicine work in NTHC? [Internet]. 2015 Feb 18 [cited $2021 \mathrm{Mar}$ ]. Available from the National Telehealth Center, https://telehealth.ph/2015/02/18/infographichow-does-telemedicine-work-in-nthc/

26. Igna HJ. PDS and NTHC collaborates, trains new specialists for Teledermatology [Internet]. 2015 Jan 21 [cited 2021 Mar]. Available from the National Telehealth Center: https://telehealth. $\mathrm{ph} / 2015 / 01 / 21 / \mathrm{pds}$-and-nthc-collaborates-trains-new-specialists-forteledermatology/

27. Carpio V, Dofitas B, Maano C, Dayrit C, Villena J, Jara M, et al. Storeand-Forward Teledermatology Using Mobile Phones: Clinical Efficacy in a Rural Primary Healthcare Centre Free Clinic Setting. JISfTeH [Internet]. 2017 Jan 28 [cited $2021 \mathrm{Mar}$; 4:e28. Available from: https://journals.ukzn.ac.za/index.php/JISfTeH/article/view/161/pdf

28. Domingo A. Updates on telehealth in the Philippines. Trans. Natl. Acad. Sci. Technol. 2002; 24:77-84.

29. Mediaarchives Philippines Inc. (MAPI) [Internet]. [cited 2021 Feb]. Available from: https://www.indeed.com/cmp/MediarchivesPhilippines-Inc.

30. Excelion Technology Inc. The Medical City partners with Excelion in RFID Launching. Philippines: Excelion Technology Inc [Internet]. 2012 Jan [cited $2021 \mathrm{Mar}$. Available from: http://www.exceliontech. com/news.php?f=001_20120120-TMC-news.

31. Philippine Information Agency. City hospital to launch Telepsychiatry. Cagayan de Oro City, Philippines [Internet]. 2016 Aug [cited 2021 Mar]. Available from: https://news.pia.gov.ph/article/view/ 2601471404796/city-hospital-to-launch-telepsychiatry

32. Philippine Information Agency. City hospital to launch Telepsychiatry. Cagayan de Oro City, Philippines [Internet]. 2016
Aug [cited 2021 Mar]. Available from: https://news.pia.gov.ph/ article/view/2601471404796/city-hospital-to-launch-telepsychiatry

33. Philippine Pharmacy Act of 2016, 16th Cong., 3rd Sess. (2016)

34. Tayapad JB, Bengzon AU, Valero SO, Arroyo MH, Papa TM, Fortuna EJS, et al. Implementation and Pilot Data on Diabetic Retinopathy in a Teleophthalmology Program at a Multispecialty Primary Care Clinic. Philipp J Ophthalmol. 2014; 39:90-3.

35. The Medical City. Department of Ophthalmology. Quezon City, Philippines: The Medical City [Internet]. 2016 [cited $2021 \mathrm{Feb}$ ]. Available from: https://www.themedicalcity.com/clinical-departments/ department-ophthalmology.

36. Grand Challenges Canada. The ctrl.para.site Project: A Medical Teleparasitology System for the Philippines [Internet]. n.d. [cited 2021 Jan]. Available from: https://www.grandchallenges.ca/granteestars/0436-01/

37. Philippine Health Research Registry. Medical Teleparasitology for Laboratory Diagnosis of Parasitic Infections in the Philippines: Optimization and Expansion of Implementation Towards Policy Formulation [Internet]. n.d. [cited 2021 Jan]. Available from: https:// registry.healthresearch.ph/index.php/registry?view=research\&layout= pdf\&cid $=2028$

38. PCARI. The Institute for Health Innovation and Translational Medicine [Internet]. 2016 [cited $2021 \mathrm{Mar}$ ]. Available from: http:// pcariofficial.blogspot.com/p/about-us_15.html\#: :text=The $\% 20$ Institute $\% 20$ for $\% 20$ Health\%20Innovation, $\% 2 \mathrm{C} \% 20$ such $\% 20$ as $\% 20$ asthma\%2C\%20diabetes\%2C.

39. Boliver, JM. DOH launches $4 / 7$ telemedicine consultations for Metro Manila residents [Internet]. 2020a April 7 [cited 2021 Mar]. Available from: https://pia.gov.ph/news/articles/1038309

40. Department of Health CALABARZON - Center For Health Development. DOH INITIATES O-HI DOC TELEDENTISTRY IN CALABARZON [Internet]. 2020 Sep 18 [cited $2021 \mathrm{Mar}$. Available from: https://ro4a.doh.gov.ph/health-profile/provincialprofile/140-featured-article/712-doh-initiates-o-hi-doc-teledentistryin-calabarzon

41. Llemit RLG. 911 telemedicine in Davao City [Internet]. 2020 Apr 26 [cited $2021 \mathrm{Mar}$. Available from: https://www.sunstar.com.ph/ article/1854118/Davao/Feature/911-telemedicine-in-Davao-City

42. Alama, RI. Teleconsultation connects patients to doctors amid pandemic [Internet]. 2020 Jun 6 [cited 2021 Mar]. Available from: https://pia.gov.ph/news/articles/1043981

43. The City of Taguig. Health [Internet]. n.d. [cited $2021 \mathrm{Mar}$. Available from: https://www.taguig.gov.ph/our-city/health/

44. Caliwan CL. Taguig launches 'telemedicine' program amid Covid-19 [Internet]. 2020 Mar 27 [cited 2021 Mar]. Available from: https:// www.pna.gov.ph/articles/1098024

45. Quezon City Government Official Website. Telemedicine [Internet]. n.d. [cited $2021 \mathrm{Mar}$. Available from: https://quezoncity.gov.ph/ program/telemedicine/

46. Boliver JM. DOH, QC LGU sets up country's first end-to-end telemedicine project [Internet]. 2020b Sep 1 [cited 2021 Mar]. Available from: https://pia.gov.ph/news/articles/1051917

47. Department of Health. DOH'S TELEMEDICINE INITIATIVES STRENGTHENS PROVISION OF PRIMARY HEALTH CARE SERVICES [Internet]. 2020 Aug 31 [cited 2021 Mar]. Available from: https://doh.gov.ph/press-release/DOH\%27S-TELEMEDICINEINITIATIVE-STRENGTHENS-PROVISION-OF-PRIMARYHEALTH-CARE-SERVICES

48. American Hospital Association. Telehealth: A Path to Virtual Integrated Care [Internet]. 2019 [cited 2021 Feb]. Available from: https://www.aha.org/system/files/media/file/2019/02/ MarketInsights_TeleHealthReport.pdf

49. Kane CK, Gillis K. The use of telemedicine by physicians: still the exception rather than the rule. Health Aff (Millwood). 2018 Dec; 37(12):1923-30.

50. Owens B. Telemedicine on the rise but lagging in Canada. CMAJ. 2018 Sep 24; 190(38):E1149-50. PubMed PMID: 30249766.

51. The Virtual Care Task-Force (VCTF). Virtual care: recommendations for scaling up virtual medical services [Internet]. $2020 \mathrm{Feb}$ [cited 2021 
Mar]. Available from: https://www.cma.ca/sites/default/files/pdf/ virtual-care/ReportoftheVirtualCareTaskForce.pdf.

52. National Initiative for Telehealth. National Initiative for Telehealth: Framework of Guidelines [Internet]. Ottawa: NIFTE; 2003 [cited $2021 \mathrm{Feb}$ ]. Available from: https://prism.ucalgary.ca/ds2/stream/?\#/ documents/9ee3d6b1-0167-4f51-beed-ad4fe3ae24b5/page/3

53. Gill M. A National Telehealth Strategy For Australia-For Discussion. Australian National Consultative Committee on Electronic Health [Intenet]. 2011 [cited $2021 \mathrm{Mar}$. Available from: https://www.who. int/goe/policies/countries/aus_support_tele.pdf

54. Wiweko B, Zesario A, Agung PG. Overview: The Development of Tele Health and Mobile Health Application in Indonesia. In: 2016
International Conference on Advanced Computer Science and Information Systems (ICACSIS); 2016 Oct 15-16; Malang, Indonesia. Malang: Curran Associates, Inc.; 2016. p. 9-14.

55. Ministry of Health (MOH) Malaysia. Malaysia Telemedicine blueprint leading healthcare into information age [Internet]. Malaysia: Telemedicine Flagship Application; 1997 July 25 [cited 2021 Mar]. Available from: https://www.moh.gov.my/moh/resources/auto\%20 download\%20images/5ca1b20928065.pdf

56. Sabrina MI, Defi IR. Telemedicine Guidelines in South East Asia - A Scoping Review. Front Neurol. 2021 Jan 13; 11:581649. PubMed PMID: 33519669.

\section{APPENDICES}

\section{eHealth Components}

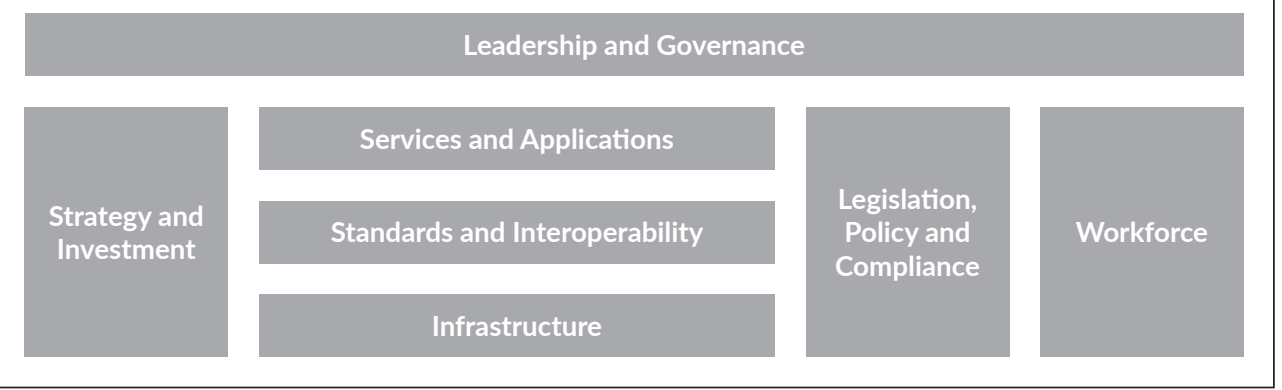

Appendix 1. eHealth Components and Building Blocks; ${ }^{4}$ adopted as Telehealth Building Blocks.

Appendix 2. Summary of eHealth Policy Domains and Relevant Policies and Programs in the Philippines

\begin{tabular}{|c|c|}
\hline Region & Number of Units Deployed \\
\hline CAR & 15 \\
\hline I & 15 \\
\hline II & 5 \\
\hline III & 9 \\
\hline IV - A & 6 \\
\hline IV - B & 16 \\
\hline V & 7 \\
\hline VI & 11 \\
\hline VII & 6 \\
\hline VIII & 24 \\
\hline IX & 3 \\
\hline $\mathrm{X}$ & 12 \\
\hline XI & 6 \\
\hline XII & 7 \\
\hline XIII & 1 \\
\hline Negros & 2 \\
\hline ARMM & 15 \\
\hline NCR & 3 \\
\hline Special Sites & Number of Units Deployed \\
\hline BJMP (Bataan District Jail) & 1 \\
\hline UP School of Health Sciences - Baler & 1 \\
\hline Manila City (M. Icasiano Health Center) & 1 \\
\hline Iloilo (Western Visayas State University) & 1 \\
\hline Iloilo (UP Visayas) & 1 \\
\hline Eastern Visayas (DOST - Region 8) & 1 \\
\hline
\end{tabular}

Source: RxBox Research Group ${ }^{19}$
Appendix 3. Distribution of additional RxBox Units Deployed as of December 31, $2020(\mathrm{~N}=369)$

\begin{tabular}{lc}
\multicolumn{1}{c}{ Institution/DOST Regional Offices } & No. of Units \\
\hline Philippine General Hospital & 40 \\
DOST National Capital Region & 50 \\
DOST Regional Office VII & 100 \\
DOST CALABARZON & 36 \\
DOST Regional Office III & 40 \\
DOST Regional Office XI & 31 \\
DOST Regional Office VIII & 71 \\
DOST Regional Office XII & 1 \\
\hline
\end{tabular}

Adapted from PCHRD Annual Report $2020^{20}$ 